\title{
Congada e Tambu: uma leitura geográfica do Patrimônio Cultural Intangível
}

\section{Congada and Tambu: a geographical reading of the Intangible Cultural Heritage}

\author{
Elisabete de Fátima Farias Silva ${ }^{1}$ \\ Bernadete Aparecida Caprioglio de Castro ${ }^{2}$
}

1 Mestranda e pesquisadora bolsista FAPESP "Geografia e música: experiências com a Congada e Tambu em Rio Claro/SP". Instituto de Geografia e Ciências Exatas da Universidade Estadual Paulista (UNESP), campus de Rio Claro. E-mail: lisafariasgeografia@gmaill.com

2 Profa. Dra. da Pós-Graduação do Instituto de Geociências e Ciências Exatas da Universidade Estadual de São Paulo, campus de Rio Claro, e orientadora desta pesquisa. E-mail: bacco@rc.unesp.br

\begin{abstract}
A Congada e o Tambu são manifestações culturais de caráter popular e tradicional existentes em Rio Claro/SP. Nessas manifestações será discutido o conceito de patrimônio cultural, através do resgate da memória coletiva dos membros atuais e mestres de outrora, seguindo a metodologia da pesquisa participante e História Oral. Os relatos coletados nesta pesquisa trazem experiências que vêm ao encontro da ideia de que, transmitido de geração em geração, o patrimônio cultural imaterial é recriado, dando ao grupo identidade e continuidade da prática. A dimensão geográfica do patrimônio cultural imaterial é pensada nesta pesquisa quanto à compreensão do tempo e espaço vividos pelos grupos da Congada e do Tambu. É a geograficidade da manifestação: as práticas e domínios da vida social no espaço que fazem deste o lugar da manifestação. As modas cantadas de improviso, os trejeitos da dança, o saber que permeia o toque do tambor, é a cultura, material e imaterialmente, manifestada na Congada e no Tambu.
\end{abstract}

Palavras-chave: patrimônio cultural intangível, lugar, Congada, Tambu.

The Congada and the Tambu are cultural manifestations of popular and traditional character that exist in Rio Claro/SP. The concept of cultural heritage will be discussed in these manifestations, through the recovery of collective memory of current members and former masters, following the methodology of participant research and Oral History. The reports collected in this research bring experiences which support the idea that the intangible cultural heritage is recreated, passed on from generation to generation, instilling in the group a sense of identity and continuity of the practice. The geographic dimension of the intangible cultural heritage is thought in this research concerning the comprehension of time and space experienced by the Congada and Tambu groups. It is the geographicity of the manifestation: the practices and areas of social life in space make this place the one for manifestation. The modes sung impromptu, the dance gestures, the knowledge permeating the beat of the drum; it is the culture, materially and immaterially manifested in Congada and Tambu.

Keywords: intangible cultural heritage, place, Congada, Tambu. 


\section{INTRODUÇÃO}

A cultura é a manifestação da expressão humana, é o que dá a humanidade uma unidade na diversidade (COUCHE, 2002). Percebida de forma diferenciada pelos grupos sociais, a cultura difunde-se, transforma-se, inventa-se. Materializada no espaço por construções e objetos e, ainda, intangível por um modo de ser e fazer, a cultura são saberes em ação, temporal e espacialmente identificáveis, remonta à oralidade, memória, tradição e costumes, identidade e patrimônio.

A moderna concepção antropológica de cultura dá ênfase, pois, "nas relações sociais ou mesmo nas relações simbólicas, mas não nos objetos e nas técnicas" (GONÇALVES, 2009, p. 30). É, assim, notável o crescente estudo dos diversos ramos do conhecimento no âmbito cultural e a busca de diálogo intraciência. Além disso, o amparo em leis, programas e projetos que tenham o objetivo de preservar - na concepção ampla do termo - a cultura se mostram fundamentais para esse processo. (SANT'ANNA, 2009).

O patrimônio cultural é entendido como um conjunto de bens que, dado o seu valor próprio, são de interesse relevante à identidade da cultura de um povo. Atualmente, o Instituto do Patrimônio Histórico e Artístico Nacional classifica o patrimônio cultural brasileiro enquanto bens materiais - móveis e imóveis - e bens imateriais ou intangíveis. Em 2006, o decreto n ${ }^{\circ}$ 5.7538, artigo 2, estabeleceu que patrimônio cultural imaterial são as "práticas, representações, expressões, conhecimentos e técnicas junto com os instrumentos, objetos, artefatos e lugares culturais que lhes são associados" das comunidades, grupos e indivíduos que os reconhecem como parte de seu próprio patrimônio cultural." (BRASIL, 2006).

Os rótulos, muitas vezes desnecessários e descabidos da teoria à prática, acabam por esbarrar na divisão cultura elite $x$ popular; cultura útil $x$ cultura fútil; alta cultura $x$ baixa cultura, entre outros. $\mathrm{O}$ fato é que a dinamicidade da cultura, seu contexto de criação e difusão e as forçantes existentes nesse processo (Estado, religião, sociedade, mídia) compõem a complexidade do campo cultural, que não é por si só e apenas um campo, mas é a vida e o sentido de sua existência, em constante transformação de valores e ideias, ameaças e horizontes, materialidade e imaterialidade.

Para Hobsbawn (1997) a tradição das invenções diz respeito a essa transformação e a cultura de um povo é a expressão disso.
Muitas vezes, 'tradições' que parecem ou são consideradas antigas são bastantes recentes.. As práticas dessas tradições "visam inculcar certos valores e normas de comportamento através da repetição, o que implica, automaticamente, uma continuidade em relação ao passado. (HOBSBAWN, 1997, p. 9-11).

Essa relação passado-presente que fala Hobsbawn (1997) ao mencionar a continuidade das tradições por meio da repetição a fim de repassar valores e normas de comportamento é percebida em várias manifestações populares. Tal processo dinâmico de continuidade e valoração da tradição faz de uma manifestação a reafirmação de identidade e memória de um povo, faz da tradição o patrimônio vivo.

A Congada e o Tambu são manifestações culturais de caráter popular e tradicional existentes em Rio Claro/SP (BRETTAS; FROTA, 2012; CASTRO, 2013; FARIA, 2011, 2014; NASCIMENTO, 2005; PEREIRA, 2008), é, pois, sobre essas manifestações que discutir-se-á o conceito de patrimônio cultural, através do resgate da memória coletiva dos membros atuais e mestres de outrora, seguindo a metodologia da pesquisa participante e História Oral. (CALDAS, 2001; HALBWACHS, 1990).

Os relatos coletados nesta pesquisa trazem detalhes "de antigamente": "oh, era assim... mas hoje não dá mais pra ser desse jeito" - comenta um mestre do Tambu; "mas isso era outros tempos, né, minha filha", diz o capitão da Congada, experiências que vêm ao encontro da ideia de que, transmitido de geração em geração, o patrimônio cultural imaterial é recriado "em função do seu meio, da sua interação com a natureza e da sua história" (IPHAN, 2006, p. 15), incutindo no grupo "um sentimento de identidade e de continuidade, contribuindo [...] para a promoção do respeito pela diversidade cultural e pela criatividade humana". (Ibidem, p. 15).

\section{OвJETIVo}

Compreender geograficamente a Congada e o Tambu - manifestações culturais populares tradicionais em Rio Claro/SP - enquanto patrimônio cultural intangível. 


\section{METODOLOGIA}

Para a execução desta pesquisa, seguiu-se a metodologia da História Oral e a vivência nos grupos como fontes de coleta, a fim de compreender geograficamente a Congada e o Tambu enquanto patrimônio cultural intangível.

A "História oral é o termo amplo que recobre uma quantidade de relatos a respeito de fatos não registrados por outro tipo de documentação, ou cuja documentação se quer completar." (QUEIROZ, 1991, p.5). A coleta acontece por meio de entrevista e pode registrar a experiência de um só indivíduo ou de vários de uma mesma coletividade. Entende-se que "tudo quanto se narra oralmente é história, seja a história de alguém, seja a história de um grupo, seja a história real, seja ela mítica." (Ibidem, p. 5).

A "Memória finita", "descoberta de novas facetas da realidade", "crítica aos dados já colhidos por outras técnicas" e "a autocrítica do pesquisador" vem se somar para caracterizar o que é a História Oral. Pela coleta da história de vida dos mestres das manifestações estudadas e depoimentos dos demais membros, o material bruto coletado demanda longo tempo, vários encontros, afinidade e confiança das partes e extensa dedicação à transcrição e, posterior, interpretação. (QUEIROZ, 1991).

Concorda-se com Caldas (2001) quando ele diz que interpretar é refletir sobre as sombras do texto; é relacionar a dialética entre a luz e a sombra do texto, da vida, da experiência, dos signos, das falas e memórias. E que, no entanto, não se pode eliminar a sombra, mas fazê-la sim existir, significar e resistir, trazê-la, não à luz, metáfora devastadora da Razão e do Olho, mas a um mundo de sombra e luz, os claro-escuros da vida, a uma vida plena de multiplicidades.

Tomou-se a metodologia da História Oral no sentido de: compreender o coletivo na narrativa individu$\mathrm{al}$; respeitar o não linear, os avanços e recuos das narrativas considerando encadeamento de toda a fala para compor e explicar a existência do ser falante e a face do fenômeno por ele visada. (HALBWACHS, 1990).

Foram coletadas cerca de 20 horas de gravação de vídeo/áudio com os membros da Congada e aproximadamente 12 horas com pessoas envolvidas no Tambu. Essas gravações são compostas por entrevistas semiestruturadas de livre consentimento dos depoentes, ensaios e apresentações dos grupos tanto na cidade de Rio Claro quanto em outros municípios.
A vivência nos grupos tem, pois, sua intenção na experiência propiciada (TUAN, 1983). Abrir-se àquele mundo e, a partir da visão de mundo da pesquisadora, conhecer, comungar, compartilhar de valores e ideias dos grupos de Congada e Tambu: Com-viver. Poderia se realizar um levantamento bibliográfico apenas, ou ainda assistir como espectadora passiva às apresentações, contudo, a escolha metodológica pela vivência enriquece o trabalho, e trazem à pesquisa e à pesquisadora novas percepções sobre o fenômeno.

Com a Congada tem-se o convívio quinzenal nos ensaios realizados no clube Tamoyo, essa vivência já passa de seis meses e pretende continuar até 2016. Foi pedido ao grupo que concedesse a participação e que, logo e gentilmente, foi aceita. Com a vestimenta do grupo blusa com babado, saia florida, turbante, flores e colares - já participei de algumas apresentações festivas neste ano. Pela proximidade alcançada foi possível entrevistar praticamente todos os trinta membros da Congada, formando assim um rico acervo dessa manifestação em sua configuração atual e memórias de outrora.

"O Tambu não tem ensaio, nunca teve, minha filha" disse um dos mestres do Batuque de Umbigada a essa pesquisadora. Em Rio Claro, procurava-se realizar o batuque a cada dois ou três meses no clube Tamoyo e, desde agosto de 2014, participou-se dos encontros, filmando, conversando com os batuqueiros e umbigando. Foram ao total cinco encontros com o batalhão da cidade e duas apresentações prestigiando outros batalhões de Tambu. Sobre o Tambu, em específico, existem alguns vídeos-documentários, como No repique do Tambu: o batuque da Umbigada Paulista ${ }^{3}$, já produzidos que também auxiliam na leitura geográfica desse patrimônio intangível.

Além da Congada e do Tambu, acompanhou-se o cotidiano do clube social negro Tamoyo com as outras atividades lá realizadas (capoeira, ensaio de mestre-sala e porta-bandeira, rodas de samba, bailão de forró, feijoadas canjas, eventos beneficentes) e demais programação organizada pela comissão do clube. Isso se deve ao convite feito a esta pesquisadora para participar da comissão

3 Este vídeo-documentário apresenta o Batuque de Umbigada das cidades paulistas Tietê, Piracicaba e Capivari, uma tradição artística herdada de escravos sobre a forte presença africana dos tambores e da dança de umbigada que se funde ao universo caipira das modas. Abarca a dura perseguição política sofrida por essa manifestação afro-brasileira. 
da diretoria a fim de "registrar a história do Tamoyo pela boca de quem vive isso" disse o presidente Humberto quando do convite, no início desse ano ${ }^{4}$.

Congada, tambu e tamoyo: paralelos e convergências nos fenômenos manifestados

\section{Congada ${ }^{5}$}

Do período da escravidão no Brasil, com as classes rigidamente segmentadas pela exclusão econômica e cultural, os africanos para cá trazidos não possuíam direito de manifestar sua religião e costumes tal qual como era em sua terra natal quando livres. Os cortejos ligados à Igreja Católica surgiram como concessão para que os negros tocassem, cantassem e dançassem, assim, foi nesse sentido que se deu o sincretismo das religiões de matriz afro e católica na manifestação Congada aqui analisada.

Dessa concessão histórica até a manifestação atual das Congadas - configuradas como se veem atualmente em cada um dos peculiares ternos, cortejos, reisados e coroações realizados em diferentes regiões brasileiras - muitas transformações ocorreram. Entretanto, a riqueza simbólica e o sentido da existência da Congada enquanto manifestação de caráter religioso afro-católica, simbolizando resistência e identidade, ainda se faz fundamentalmente presente. O cantar, o dançar, o tocar, o expressar-se dramaticamente na coroação de reis são costumes africanos, localizáveis entre os congueses propriamente, Mário de Andrade (1959) comenta a figura dos reis na tradição dessa manifestação em terra brasileira:

Não se trata de usanças meramente fantasistas. Só os reis ânuos parecem mesmo imposição alheia às tradições,

4 Sobre esse lugar, em específico, será apresentado no XI ENANPEGE - Presidente Prudente/SP, de 9 a 12 de outubro de 2015 - o seguinte trabalho: "Um lugar, várias identidades: o Tamoyo, clube social negro em Rio Claro/ SP", de autoria de Elisabete F. F. Silva e Bernadete A. C. de Castro.

5 O Congado designa a reunião de todos os ternos Moçambique, Congo, Catopés, Marujos, Cabloquinhos, entre outras denominações - que através do bailado típico, do som dos tambores e dos cânticos representam a manifestação. (BRETTAS; FORTA, 2012, p. 36). No entanto, em muitas localidades como no estado de São Paulo, por exemplo, o terno também é conhecido como Congada. Congo(s), o(s)/a(s) Congad(o/os/a/as) dizem respeito a mesma manifestação. (ANDRADE, 1959). criada pela facilidade cronológica que isso trazia, fazendo coincidir as festanças de eleição do reis novo com as datas católicas em que era de praxe darem maior folga à negrada. (ANDRADE, 1959, p. 23).

Nas pesquisas de Mário de Andrade, no capítulo "Os congos" do livro "Danças dramáticas no Brasil", o autor descreve acerca das características da manifestação Congada com base em documentos históricos e em experiências próprias. Sendo uma obra de referência, Andrade (1959) expõe a trama histórica desse patrimônio cultural.

Atualmente, de maneira geral, o "terno", sendo também denominado "guarda" ou "corte", é representado por grupos diversos, e se distingue pela vestimenta, coreografia e ritmo do batuque. Em datas festivas, principalmente relacionadas a santos negros da Igreja Católica, organizam-se em cortejo vários ternos diferentes: caminham pelo percurso estabelecido da casa dos festeiros (devotos que recebem os congueiros, abrem suas casas, dão alimento/bebida/ hospedagem aos ternos, mostram suas imagens de santos em devoção) à igreja e vice-versa. Quando do início do cortejo, são apresentados simbolicamente as figuras do Rei e da Rainha congos, que representam o elo com a ancestralidade africana, há também os chamados Rei e Rainha Perpétuos (BRETTAS; FROTA, 2012, p. 35). Os membros que figuram esses personagens em geral são escolhidos anualmente e são ligados à Igreja Católica e aos movimentos negros (Irmandade de São Benedito e/ou de Nossa Senhora do Rosário, Pastoral Afro e movimentos culturais da sociedade civil). Todos os ternos prestam homenagens e reverenciam com cortejos, danças, cânticos e toques de tambores ao reisado: "tudo isso faz parte de compromissos rituais e sagrados com os santos de devoção". (Ibidem, p. 36). Contudo, vale-se destacar que, concordando com os autores:

Essa manifestação não revela somente traços da cultura negra, mas parte da cultura brasileira. O Congado é realizado em vários pontos do Brasil miscigenado, e revela valores e aspectos simbólicos característicos das comunidades que o realizam, bem como informações históricas a respeito da formação e evolução da religiosidade e dos aspectos culturais e geosimbólicos, em várias regiões do país. Assim, é crucial que ele seja registrado e preservado, ação essa que deve ser realizada por instituições ligadas ao Poder Público e representantes da sociedade civil. (BRETTAS; FROTA, 2012, p. 40). 
Se, historicamente, foram os negros aqui escravizados que levaram os andores pesados dos santos da Igreja católica em longos cortejos, no período colonial, e na figura dos reis negros ressignificavam a diáspora africana, hoje a manifestação do património cultural Congada tem novos sentidos. O que revela, inclusive, a cultura brasileira de miscigenação e sincretismo em desdobramento nas diversas regiões, tal como apontam os autores. A Congada é uma manifestação da religiosidade e cultura popular muito expressiva em números, espacialidade e diversidade pelo território brasileiro, muitos outros pesquisadores apontam a necessidade do registro e preservação desse patrimônio.

No caso da Congada de Rio Claro/SP, a divisão em alas é nítida nos cortejos:

- Uma porta-estandarte que empunha um lindo estandarte pintado a mão e que leva o nome e a imagem do santo de devoção do grupo e dados da Congada (Grupo Folclórico Congada e Tambu de São Benedito de Rio Claro/SP).

- Três homens que levam bandeiras de cunho político-territorialistas (Brasil, São Paulo, Rio Claro), quando perguntado sobre a origem dessa tradição, em específico, não souberam datar ao certo nem nomear quem iniciou a ideia de levar as bandeiras, fato é que não se percebeu essa tendência em outros ternos já vistos pela pesquisadora. O que revela, em parte, a fala constante dos membros, "queremos levar o nome de Rio Claro/SP para onde formos... mostrar que se valoriza a cultura em Rio Claro", o que de certa forma está incutido pela fomentação financeira que o município concede mediante a subvenção nos últimos três anos e a espetacularização da manifestação mostrando-se enquanto prevalência de questões políticas em detrimento da identidade social simbolizada no cortejo e na união das pessoas agrupadas em torno do que lhes é comum e fazem sentido à existência desse grupo de Congada e Tambu.

- Rei e Rainha, com roupas e adornos bem característicos, esses personagens trazem em si um dos significados que está na origem dos primeiros cortejos da qual outras manifestações se desdobraram, ou seja, a coroação dos reis - escolhidos e dignos de governo. Na Congada estudada, esses personagens perderam tal sentido, inclusive já houve apresentações de não ter quem fizesse esse papel, pois os que faziam não eram comprometidos com o grupo assiduamente nem eram pessoas "velhas e experientes" de grande representatividade para o coletivo, como acontece em outros ternos já observados. "Nas Congadas paulistas de agora, onde o reis perdeu completamente o sentido social que teve durante a escravidão, a dignidade geralmente permanece enquanto o sujeito vive", já diferenciava Mário de Andrade (1959, p. 22) em razão das características essenciais visualizadas nos Congos do Nordeste e de Minas Gerais por ele pesquisados.

- Capitão, esta figura adquire importância peculiar nesse grupo, seu Ariovaldo toma a frente da administração, da guarda e manutenção dos instrumentos, dos ensaios, da agenda de apresentações, da burocracia devido à subvenção municipal e tudo o mais. Concentra em si muitas tarefas e responsabilidades, além de apitar o andamento do cortejo quando das apresentações, o capitão é o mestre, o guia. O que conhece os segredos e as histórias de outros tempos, da magia do ritual e da simbologia de cada gesto. Seu Ariovaldo é uma figura muito interessante, e quem vê esse capitão dificilmente se esquece, um senhor negro, alto, simpático, polido e respeitado. "Tudo o que eu tenho foi porque lutei, lutei, lutei e lutei minha filha" - disse repetidamente em várias das entrevistas realizadas para a pesquisa: o guerreiro e a liderança se mostram não só na farda, mas na vida desse homem que conduz a Congada de Rio Claro.

- Dançantes, quatorze mulheres divididas em duas filas dando rodopios, mexendo as saias e sorrindo para os festeiros que acompanham o cortejo ao som do batuque. De turbante e roupa bem chamativa, os colares e a chita da saia dão ao terno um diferencial. Cada uma delas leva consigo um bastão que, quando da parada do cortejo, cruzam-se batendo em sinal da guarda e proteção aos reis. Nessa Congada o mais interessante é que, em sua maioria, é formada por pessoas da terceira idade. A mais nova é esta pesquisadora que está a participar e os meninos batuqueiros que às vezes são levados pelos avôs também membros do grupo; os mais velhos são seu Martins, 80 anos, que participa desde a primeira formação dessa Congada, e dona Vera, 81 anos, que há pouco se mudou para 
Rio Claro e entrou para o grupo em 2014. Existem ternos compostos, predominantemente, por crianças, outros por jovens, vários por adultos, mas por pessoas de terceira idade esse foi o único que se teve contato desde o início da pesquisa. Em muitas apresentações foram elogiadas as vestimentas e a alegria do grupo formado por idosos que se destacam perante os outros por esses quesitos.

- São de três a cinco batuqueiros que tocam caixas, bumbos, repique de mão e guaiás. Uma das reclamações do grupo é a falta de batuqueiros, geralmente nos ternos de Congada mais da metade do grupo são de batuqueiros, alguns grupos também tocam, além de instrumentos percussivos, instrumentos melódicos, como violão, sanfona, violino e gaita.

Para além dessa descrição, as relações sociais que envolvem a Congada - os saberes, os fazeres - compõem essa manifestação cultural popular tradicional enquanto patrimônio intangível pela ligação existente com e entre a comunidade no sentido de oralidade, memória e identidade. Brettas e Frota (2012) destacam que:

No caso das celebrações afro-brasileiras, elas representam meios de sobrevivência dos vestígios da memória africana, durante séculos de sua repressão social e cultural nas colônias americanas. Através das performances rituais, podem ser vislumbrados alguns dos processos de criação de suplementos que buscam cobrir as faltas, vazios e rupturas das culturas e dos sujeitos que se reinventaram. (BRETTAS; FROTA, 2012, p. 34).

O sentido das relações sociais estabelecidas na cultura é essencial para

\section{Tambu}

Essa manifestação tem como base o batuque (levado pelo Tambu ou o "sete léguas" - assim chamado porque se ouvia a sete léguas de distância das senzalas de onde era comumente tocado - quinjengue, matraca e guaiá), pela dança (enfileirados, homens de um lado e mulheres de outro, os corpos dão volteios e umbigam três vezes com o mesmo parceiro e depois trocam-se os casais) e pela "moda" (letra, comumente de autoria coletiva, que versa sobre o cotidiano em diversos temas, existe ainda a modalidade do improviso que garante à manifestação riqueza, especificidade e acontecimentos surpreendentes - cada encontro é único).
Outras manifestações culturais são levadas pelos batuques exclusivamente percussivos, outras também têm o gesto da umbigada, além de outras que apresentam as modas e os improvisos, entretanto, tal como se manifesta no Tambu só a ele pertence. Quem ouve um Tambu - instrumento feito a partir de tronco de árvore em peça única, escavado manualmente, com pele de animal e afinado pela aguardente e fogo, mede cerca de 1,5 m, é forte, robusto, "fala alto" - se lembrará, dizem os batuqueiros. Para finalizar a festança, a tradicional canja é servida, já madrugada adentro, aos batuqueiros e a todos os outros que prestigiaram o encontro.

Fazer o Tambu é uma arte, a escolha e coleta da madeira, o trato, o fogo e muito tempo de dedicação no acabamento e finalização do tambor ancestral; tocar o Tambu é uma arte, "não é qualquer um que põe a mão aqui não" diz com seriedade um dos batuqueiros de Rio Claro; dançar e cantar ao Tambu são manifestações do religare à natureza, à origem da vida: a madeira naturalmente sagrada que ao passar pelas mãos humanas torna-se objeto transformado, também sagrado; os corpos que se ligam um ao outro pelo ventre, pela fertilidade, pela celebração da divino encontro entre os pares diferentes e complementares.

O Tambu tem origem nos povos Bantus, que são ali da região de Angola, é uns povo que eles curtiam muito o tambor. O tambor é considerado como um santo, uma entidade para eles, porque tudo gira em torno dele, ele que produz a energia. (DANÇAS AFROBRASILEIRAS... 2011).

A umbigada é uma dança que chegou ao Brasil a partir do século XVII, com os negros africanos trazidos como escravos pelos colonizadores portugueses. No estado de São Paulo é uma dança comemorativa ou tributo de terreiro praticados pelos remanescentes das senzalas paulistas. A dita "região batuqueira" paulista localiza-se no Vale do Médio Tietê, abrangendo alguns municípios, como Tietê, Porto Feliz, Laranjal, Pereiras, Capivari, Botucatu, Piracicaba, Limeira, Rio Claro, São Pedro, Itu, Tatuí. Em Campinas era chamado Caiumba, segundo registro do maestro Carlos Gomes. (MORETTI, 2012).

A afinação dos tambores é obtida por aquecimento do couro em fogueira que preside toda a dança. $\mathrm{O}$ tocador do tambu monta sobre o instrumento e bate no couro com as mãos espalmadas; o quinjengue fica apoiado no 
tambu e fixo entre as pernas do tocador, que inclina e percute o couro também com as mãos; na parte posterior do tambu fica o tocador de matraca, agachado ou encurvado, batendo com os paus no corpo desse tambor; o guia geralmente circula entre os cantores. (Ibidem, p. 6).

Originalmente, o Tambu celebrava casamentos, aniversários e festas em geral. A partir de 1888, os dias 13 de maio eram então comemorados por grandes festas de Tambu, samba-lenço e cururu em comemoração à assinatura da Lei Áurea e abolição da escravatura.

Atualmente o Tambu passou por modificações, mas pode-se afirmar que foram poucas e não substanciais à essência da manifestação, por exemplo acontecer além do 13 de maio, dar mais do que três umbigadas com o mesmo parceiro, poder participar homens e mulheres que estejam usando roupas não características da manifestação (como homens de bermuda ou mulheres de calça comprida), ou ainda a cantoria das modas ser microfonada e o local de apresentação não ser aberto e de chão batido (acontecendo em salões fechados atualmente em Rio Claro). A participação de muitas pessoas de pele branca, de diferentes classes sociais, e ampla divulgação dos eventos também revelam a maior aceitação que essa manifestação tem ganhado nas últimas décadas, diferente dos séculos XVII, XVIII, XIX e até do XX quando marginalizada e considerada vadiagem e dança promíscua pelo gesto imoral da umbigada. $\mathrm{O}$ Tambu foi tratado como "caso de polícia" na primeira metade do século XX em Rio Claro como se têm relatos documentados no Arquivo Público Histórico e Municipal ("Caso Copriva").

Entre idas e vindas, ocultamentos e exposições, o Tambu tem registros orais de festas antes de 1905 em Rio Claro, ano de inauguração da Igreja de São Benedito, construída com o objetivo de acabar com as manifestações de matriz afro que aconteciam naquela área conhecida no período como Quilombo, dado o aglomerado de negros que ali viviam. Supõe-se que, pelo histórico escravista de Rio Claro (DEAN, 1977), o Tambu tenha ocorrido muito antes, entretanto, devido à marginalização dessa manifestação, a tradição oral não fora registrada e acabou por se perder no tempo com a morte dos batuqueiros mais antigos. Os dados que se têm sobre o início do século XX são de membros da comunidade negra falando sobre seus pais, avós e o que ouviram sobre suas bisavós.
Com um histórico que não cabe neste texto, destaca-se apenas que a manifestação parou de acontecer "ficou esses 50 anos sem ninguém levar devido a intrigas na comunidade e desconfiança que a liderança tivesse ganhando dinheiro", disse o batuqueiro Malvino sobre quando seu pai "puxava" a festa por volta de 1950, e voltou a ocorrer em 2003, levada por alguns descendentes dos antigos mestres batuqueiros que chegaram a frequentar a festa quando criança em parceria com a Pastoral Negra da cidade. (NASCIMENTO, 2005).

Houve uma iniciativa popular pelo resgate da tradição, jovens e idosos associaram-se pelo saber e fazer cultural, após conversar com os mais antigos para aprender sobre o Tambu, marcaram-se ensaios e eis que o Tambu se manifestou novamente: "Então no dia da posse do 'Q' no Centro Cultural, foi a primeira vez depois de 40 anos que dançamos o Tambu", disse a griô Dona O. (NASCIMENTO, 2005, p. 51).

Percebe-se que as décadas nos relatos não coincidem, assim como não coincidem outras especificidades da organização da festa e nomes dos batuqueiros mais antigos, a memória e o contexto se fazem presentes/ausentes (HALBWACHS, 1990), contudo, coletivamente não escondem o reconhecimento dessa manifestação cultural tradicional, o Batuque de Umbigada, patrimônio intangível que nos últimos anos vem sido buscado pela comunidade em processo espontâneo, sendo, assim, repensado, revivido, ressignificado, recriado.

Algumas pesquisas já abordaram os espaços negros dessa manifestação (CASTRO, 2013; DEAN, 1977; FARIA, 2011, 2014; NASGIMENTO, 2005; PEREIRA, 2008), que desde os últimos três anos vem acontecendo no clube Tamoyo.

Em 2012, o Tambu foi contemplado com o Programa de Ação Cultural (ProAC) da Secretaria da Cultura do Governo do Estado de São Paulo, pela inciativa de Ivan Bonifácio - batuqueiro que se mostra à frente para organizar os encontros e dialogar com os batalhões de Capivari, Tietê e Piracicaba, cidades que também têm suas idas e vindas com o Tambu e estão preservando a memória por meio de oficinas, apresentações diversas, produção de CD e livros e parcerias com secretarias municipais da cultura, da educação e institutos de pesquisa e divulgação da cultura. Pode-se ver uma "safra nova de batuqueiros" nascendo. Em 2014, novamente o ProAC foi acessado por Ivan, dessa vez para produção de um livro com o objetivo de resgatar os toques de cada 
batuqueiro de Rio Claro e região e o fazer do Tambu - ambos objetivos com importância ímpar dentre o universo de conhecimentos dessa manifestação.

A Congada e o Tambu apresentam convergências quanto aos mestres, aos lugares, aos contextos (Figura 1). Em 2012 e 2013 algumas vezes se apresentaram juntos, o grupo de seu Ariovaldo também toca Tambu em algumas apresentações fora da cidade e cantam, por vezes, as mesmas músicas/modas já que são de criação coletiva e domínio público. Como a moda a seguir, que é uma moda de saudação, entrada, licença às entidades espirituais do lugar em que a manifestação está por acontecer.
Licença para os tambores tocarem e para os corpos dançarem, licença para o tambor ser um Corpo e o corpo ser um Tambor. Sincretismo religioso, louvor, incenso, cheiro, casa, elementos da natureza, pequeno trecho muitos sentidos:

Quando nessa casa entrei,

Quando nessa casa entrei eu louvei Maria.

Quando nessa casa entrei,

Quando nessa casa entrei eu louvei a luz do dia.

Senhora do Rosário a sua casa cheira,

Cheira cravo e cheira rosa, cheira à flor de laranjeira.

Figura 1. Manifestação cultural do Tambu e da Congada, aproximações ocorridas em Rio Claro.

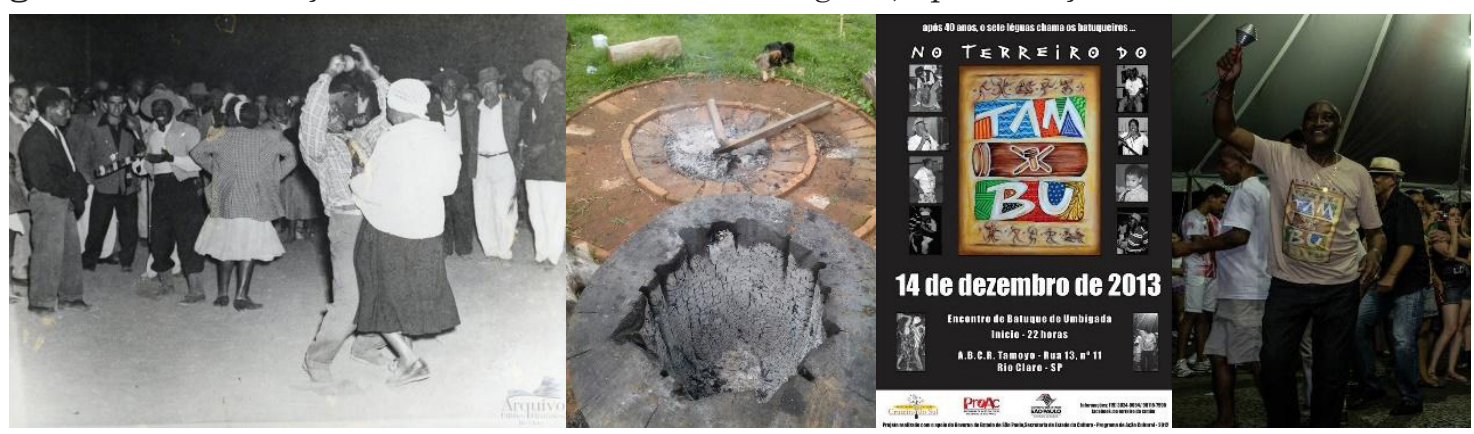

(A)

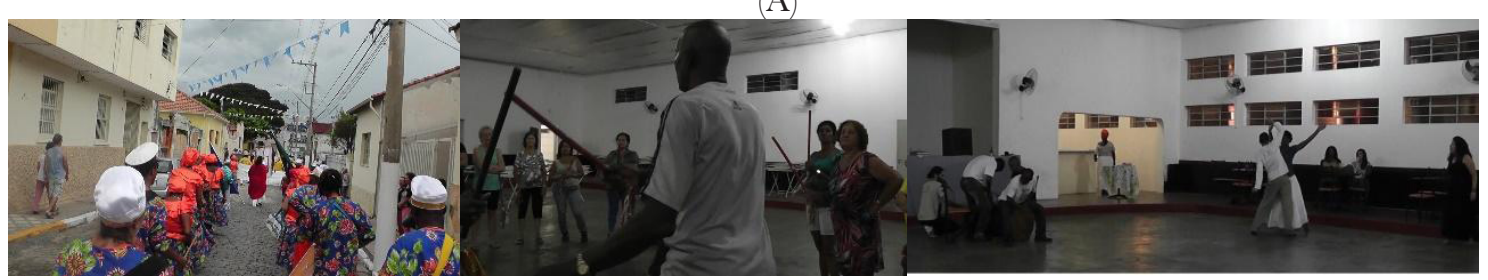

(B)

Fonte: (A) Acervo do Arquivo Público e Histórico do Município de Rio Claro.

(B) Acervo da autora.

Nota: (A) Da esq. para dir.: Umbigada em 195?, acervo do APHM; Tambu sendo feito por Ivan Bonifácio; Folder do grande evento realizado em 2013; Capitão da Congada sr. Ariovaldo participando do Tambu em 2013;

(B) Da esq. para dir.: Congada em cortejo, Guaratinguetá/SP, abril/2015; Ensaiando Congada no clube social negro Tamoyo; Encontro de Tambu também no clube Tamoyo, março/2015.

\section{Tamoyo - o lugar}

O clube social negro Tamoyo é uma associação beneficente cultural e recreativa fundado em 1952, na cidade de Rio Claro. É um símbolo no espaço por igualdade e reconhecimento da luta de outrora e de hoje. Cada tijolo da construção realizada pelos vários mutirões foi depositado por mãos negras e levaram consigo o sonho e projeto de se ter um lugar onde fosse de livre manifestação cultural, já que os clubes da elite branca local proibiam a entrada e mesmo a circulação nos espaços públicos tinham "restrições sociais" para os negros. O Tamoyo faz assim parte da história de resistência cultural e de 
conquistas do movimento negro. (ESCOBAR, 2010). O lugar, menção ao pertencimento e acolhimento da comunidade que não quer mais se sentir à margem - o que atualmente não se liga exclusivamente aos negros da cidade - permeia a análise geográfica. A pesquisa com a Congada e o Tambu acabou trazendo esta pesquisadora ao Tamoyo e mostrando a cada festa, limpeza de salão ou ensaios corriqueiros a dinâmica cultural levada pelo povo se manifestando no espaço, referindo-se à resistência, coletividade, identidades e patrimônio, fazendo daquele local o seu lugar. O Tamoyo compreende em si relações culturais intangíveis de outros tempos, rememoradas no presente com intenção de continuidade futura, um galpão que abriga mundos.

\section{ConClusão}

Os bens culturais têm sido analisados na Geografia nos últimos anos, "sinalizando para um rico caminho teórico e investigativo a ser seguido no âmbito da própria ciência geográfica e em diálogo permanente com áreas afins, como a História, a Arquitetura e a Antropologia." (FIGUEIREDO, 2013, p. 56). Fato anteriormente negligenciado pela falta e/ou fragilidade na concepção da dimensão cultural do espaço. Os anos 1970, a partir das críticas às bases positivistas, iniciaram a relevância das dimensões simbólicas dentro do processo de renovação da ciência geográfica, que se deu tanto em referenciais marxistas, como humanistas. (NIGRO, 2010).

Seguindo as referências humanistas, a pesquisa que ainda se encontra em desenvolvimento deparou-se com as informações orais muitas vezes destoantes ou mesmo contraditórias entre si em alguns pontos. Seja quanto à história dos grupos estudados, líderes, locais de execução, instrumentos, canto e dança, seja quanto ao objetivo do grupo e noção de cultura por cada um dos membros que fora entrevistado. E, por ter se optado por recolher vários depoimentos, o intuito não é, de sobremaneira, a eleição de uma delas como verdadeira. As falas dos entrevistados têm a presença de uma existência única, um olhar sobre o fenômeno:

O real e o natural não são instâncias de realidade que independem de qualquer presença: sem uma práxis não existe mundo; e podemos perguntar: sem a práxis existirá um mundo de que forma? Com qual forma? Com qual imagem? Com qual sentido? Com qual significado? Como falar em mundo, em cosmo sem um olho, sem uma "comunidade" (termo que precisa sempre estar entre aspas), sem uma existência? (CALDAS, 2001, p. 25, grifo do autor).

Diferentemente das concepções tradicionais, não se propõe o tombamento dos bens de patrimônio cultural intangível, a proposta existe no sentido de registrar essas práticas e acompanhá-las para verificar sua permanência e suas transformações (GONÇALVES, 2009). O objetivo é manter o registro da memória e de sua trajetória no tempo: "Os bens culturais de natureza imaterial são dotados de uma dinâmica de desenvolvimento e transformação que não cabe nesses conceitos, sendo mais importante, nesses casos, registro e documentação do que intervenção, restauração e conservação." (SANT'ANNA, 2009, p. 55).

A Congada foi "inventada" e reelaborada pela Pastoral Negra e pela Irmandade de São Benedito esta última desativada atualmente - na década de 1970. O Tambu vem sendo levado em Rio Claro em diálogo com outras cidades que, de alguma forma, resgataram com antecedência essa tradição. A partir da vivência nesses grupos, teve-se a compreensão da afirmação de Hobsbawn (1997, p. 21): "Isso porque toda tradição inventada, na medida do possível, utiliza a história como legitimadora das ações e como cimento de coesão grupal."

A dimensão geográfica do patrimônio cultural imaterial é pensada nesta pesquisa quanto à compreensão do tempo e espaço vividos pelos grupos da Congada e do Tambu. É a geograficidade da manifestação: as práticas e domínios da vida social no espaço que fazem deste o lugar da manifestação (HOLZER, 2003, 2010; TUAN, 1983). As modas cantadas de improviso, os trejeitos da dança, o saber que permeia o toque do tambor, é a cultura, material e imaterialmente, manifestada na Congada e no Tambu, na identidade, na memória, no lugar.

\section{REFERÊNCIAS}

ANDRADE, M. Os congos. In: Danças dramáticas no Brasil. 2 tomo. São Paulo: Livraria Martin, 1959. p. 8-135.

\section{BRASIL. A trajetória da salvaguarda do patrimônio cultural imaterial no Brasil: 1936-2006. Brasília, DF: Departamento do Patrimônio Imaterial, 2006. Disponível em: <http://portal.iphan.gov.br/uploads/publicacao/}


PatImaDiv_OsSambasAsRodasBumbas_1edicao_m. pdf $>$. Acesso em: 1 maio 2015.

BRASIL. Decreto n. 5753, de 12 de abril de 2006. Promulga a Convenção para a Salvaguarda do Patrimônio Cultural Imaterial. Brasília, DF: Presidência da República, 2006. Disponível em: < http:/ / www.planalto.gov.br/ccivil_03/_ato2004-2006/2006/ decreto/d5753.htm>. Acesso em: 1 maio 2015.

BRETTAS, A. P.; FROTA, M. G. da C. O registro do Congado como instrumento de preservação do patrimônio mineiro: novas possibilidades. Revista Eletrônica do Programa de Pós-Graduação em Museologia e Patrimônio - PPG-PMUS UniRio/MAST, v. 5, n. 1, 2012. Disponível em: < http://revistamuseologiaepatrimonio.mast.br/index.php/ppgpmus/article/ view/138/176>. Acesso em: 1 maio 2015.

CALDAS, A. L. Nas águas do texto: palavra, experiência e leitura em história oral. Porto Velho: EDUFRO, 2001.

GASTRO, B. A. C. de. Patrimônio cultural e territorialidade negra em Rio Claro-SP. Espaço \& Geografia, Brasília, v. 16, n. 2, p. 557-578, 2013. ISSN: 1516-9375. Disponível em: <www.lsie.unb.br/espacoe geografia/ index.php/espacoegeografia/.../194>. Acesso em: 1 out. 2014.

COUCHE, D. A noção de cultura nas ciências sociais. Tradução de V. Ribeiro. Bauru: Ed. da USC, 2002.

DANÇAS AFRO-BRASILEIRAS na cidade de Rio Claro: o batuque de Umbigada e a Congada de São Benedito [2011]. Entrevistador: Daniel Moi. Rio Claro: Arquivo Público Histórico Municipal de Rio Claro, 2011 (9'55", son., color). Disponível em: < http://memoriaviva.sp.gov.br/site/as-dancas-afro-brasileiras-nacidade-de-rio-claro-o-batuque-de-umbigada-e-a-congada-de-sao-benedito-2011/>. Acesso em: 28 maio 2014.

DEAN, W. Rio Claro: um sistema brasileiro de grande lavoura 1820-1920. Tradução de W. M. Potinho. Rio de Janeiro: Paz e Terra, 1977.
ESCOBAR, G. V. Clubes sociais negros: lugares de memória, resistência negra, patrimônio e potencial. 2010. Dissertação (Mestrado em Patrimônio Cultural) - Universidade Federal de Santa Maria, Santa Maria, 2010 .

FARIA, M. M. de. Resistir e fixar: a formação de negros territórios e suas manifestações na cidade de Rio Claro-SP. 2011. Trabalho de Conclusão de Curso Universidade Estadual "Júlio de Mesquita Filho", Rio Claro, 2011.

\section{Valorização dos percursos}

negros no Brasil: perspectivas de educação nos territórios afro-rioclarenses. 2014. Dissertação (Mestrado em Educação) - Universidade Estadual Paulista "Júlio de Mesquita Filho", Rio Claro, 2014.

FIGUEIREDO, L. C. Perspectivas de análise geográfica do patrimônio cultural: algumas reflexões. Geografia Ensino \& Pesquisa, Santa Maria, v. 17, n. 1, jan./ abr. 2013. ISSN 2236-4994. Disponível em: <http:// periodicos.ufsm.br/geografia/article/view/8739/ pdf $>$. Acesso em: 1 jun. 2015.

GONĢALVES, J. R. S. O patrimônio como categoria de pensamento. In: ABREU, R.; CHAGAS, M. (Orgs.) Memória e patrimônio: ensaios contemporâneos. 2. ed. Rio de Janeiro: Lamparina, 2009. p. 25-33.

HALBWACHS, M. A memória coletiva. São Paulo: Vértice, 1990.

HOBSBAWN, E. Introdução: a invenção das tradições. In: HOBSBAWN, E.; RANGER, T. (Orgs.). A invenção das tradições. 3. ed. Rio de Janeiro: Paz e Terra, 1997. p. 9-24.

HOLZER, W. A construção de uma outra ontologia geográfica: a contribuição de Heidegger. Associação de Geografia Teorética, Rio Claro, v. 35, p. 241251, 2010.

O conceito de lugar na geografia cultural-humanista: uma contribuição para a geografia contemporânea. GEOgraphia, Niterói, v. 5, n. 10, p. 113$123,2003$. 
MORetTi, E. S. A umbigada do Mestre Aggêo: uma breve história sobre o Batuque de Umbigada em Barueri. Barueri: Secretaria de Cultura e Turismo de Barueri, 2012.

NASCIMENTO, Â. S. Os espaços negros na cidade de Rio Glaro/SP. 2005. Trabalho de Conclusão de Curso - Universidade Estadual "Júlio de Mesquita Filho", Rio Claro, 2005.

NIGRO, C. As dimensões culturais e simbólicas nos estudos geográficos: bases e especificidades da relação entre patrimônio cultural e geografia. In: PAES, M. T. D.; OLIVEIRA, M. R. da S. (Orgs.). Geografia, turismo e patrimônio cultural. São Paulo: Annalube, 2010. p.55-80.

NO REPIQUE do Tambu - O batuque de Umbigada Paulista. Direção: Paulo Dias e Rubens Xavier, Coprodução: TV Cultura e Rede SESG/SENAG de TV. 2003. $58 \mathrm{~min}$.
PEREIRA, F. A. de S. Organizações e espaços da raça do Oeste Paulista: movimento negro e poder local em Rio Claro (dos anos 1930 aos anos 1960). 2008. Tese (Doutorado em Sociologia) - Universidade Estadual de São Carlos, São Carlos, 2008.

QUEIROZ, M. I. P. de (Org.). Variações sobre a técnica de gravador no registro da informação viva. São Paulo: T. A. Queiroz, 1991.

SANT'ANNA, M. A face imaterial do patrimônio cultural: os novos instrumentos de reconhecimento e valorização. In: ABREU, R.; CHAGAS, M. (Orgs.). Memória e patrimônio: ensaios contemporâneos. 2. ed. Rio de Janeiro: Lamparina, 2009.

TUAN, Y. Espaço e lugar: a perspectiva da experiência. Tradução de L. de Oliveira. São Paulo: DIFEL, 1983. 